\title{
An Application of Interest Driven Teaching Approach in Mechanics of Material Course
}

\author{
Man Hu, Fei Wu, Shiji Wang \\ College of Engineering and Technology, Southwest University, Chongqing, China
}

Email address:

humanyyyes@126.com (Man Hu)

To cite this article:

Man Hu, Fei Wu, Shiji Wang. An Application of Interest Driven Teaching Approach in Mechanics of Material Course. Science Journal of Education. Vol. 6, No. 2, 2018, pp. 46-49. doi: 10.11648/j.sjedu.20180602.11

Received: January 16, 2018; Accepted: March 13, 2018; Published: April 16, 2018

\begin{abstract}
Mechanics of Material is an important professional foundation course for engineering students. While the content of the course is wide-range, boring and abstract, a decline in interest for this course and also the decline in understanding of mechanics have been noticed in the teaching and learning activities. The traditional methods of teaching, which are mainly based on the theoretical interpretation, could not promote the interest of students in learning this kind of courses such as Material Mechanics, and then they cannot contribute enough to change this situation. To solve the problem, a so-called interest driven teaching method was herein presented. This paper sketches the characteristics of the interest driven teaching method. Taking Material Mechanics as an example, the learning problems and interest points of students in the course were extracted and summarized. A variety of strategies of promoting the learning interest of students has been put forward on the basis of practical teaching experience and verification. The presentation of the interest driven teaching method in the classroom has increased the interest of college students for learning Mechanics of Materials.
\end{abstract}

Keywords: Interest, Teaching Method, Material Mechanics

\section{Introduction}

Mechanics of materials is a professional basic course closely integrated with theory and practice. It focuses on developing students' ability to analyze the strength, stiffness and stability of the materials in engineering design [1]. In the traditional form of teaching, the learning approaches of students are mainly passive, so that they lacks the positive learning attitude, method and activities, such as analysis and discussion, comprehensive summarization, questioning and so on. In addition, although the content of material mechanics is closely related to practical engineering, students do not understand how to abstract practical engineering problems into mechanical models and conditions. Therefore, the innovative thinking of students should be cultivated, and the abilities of students to solve practical engineering problems with the application of materials mechanics should be improved. The traditional teaching approach thus should be added new content and made breakthrough, and interest driven teaching method aim to stimulate the interest of learning of students, which can be a breakthrough point for solving the problem [2].
As Einstein said, "interest is the best teacher". The motivation for students to learn may be more or less influenced by factor of the interest [3]. Nicol states that student motivation is influenced by personal needs and values, what the students believe they can accomplish and expectations of success or failure [4]. Students can find out and fulfill their personal needs and values by immersing in the field they are interested in. In this paper, the interest driven teaching approach with "arousing students' interest in learning" as the ultimate goal enables students to change from passive acceptance learning way to active voluntary self-learning way.

\section{Key Points and Difficulties of the Course}

Through the teaching observations, discussions and questionnaire survey for more than 200 students in two years, the key points and difficulties of the course were extracted and sorted according to the analysis and interpretation of the teaching situation in the classroom, the completion of the 
homework and the students' interest points. The survey data and explanations are shown in Table 1.

Table 1. An analysis of the main problems of the course.

\begin{tabular}{|c|c|c|c|}
\hline Major problem & Characteristics & Proportion & Explanations \\
\hline Curriculum difficulty & $\begin{array}{l}\text { Generally difficult } \\
\text { Very difficult }\end{array}$ & $\begin{array}{l}52 \% \\
27 \%\end{array}$ & The course content is boring and abstract. Homework is difficult. \\
\hline Reception & $\begin{array}{l}\text { It can be understood in class but it is } \\
\text { difficult to finish the homework }\end{array}$ & $85 \%$ & The exercises in the classroom and after-school are insufficient. \\
\hline Homework completion & Independent completion & $21 \%$ & $\begin{array}{l}\text { Homework is more difficult than classroom practice. Lack of the } \\
\text { abilities to draw inference about other cases from one instance. }\end{array}$ \\
\hline $\begin{array}{l}\text { The least interesting } \\
\text { content }\end{array}$ & $\begin{array}{l}\text { Bending stress and deformation } \\
\text { Stress state of unit body } \\
\text { Statically indeterminate problems }\end{array}$ & $\begin{array}{l}26 \% \\
61 \% \\
78 \%\end{array}$ & $\begin{array}{l}\text { The purpose of learning is not clear, and the content is abstract. It is } \\
\text { necessary to make clear the purpose of learning, and pay attention to } \\
\text { the close combination of practice and theory. }\end{array}$ \\
\hline
\end{tabular}

\section{Interest and Teaching Strategies}

Aiming at the core and the most difficult part of the course, the authors have carried out long-term teaching exploration and practice verification. Through various teaching strategies, the interest of students has been lifted in three aspects, interest in real life, interest in virtual world and interest in communication with classmates. The detailed teaching strategies in the three parts are shown in Figure 1.

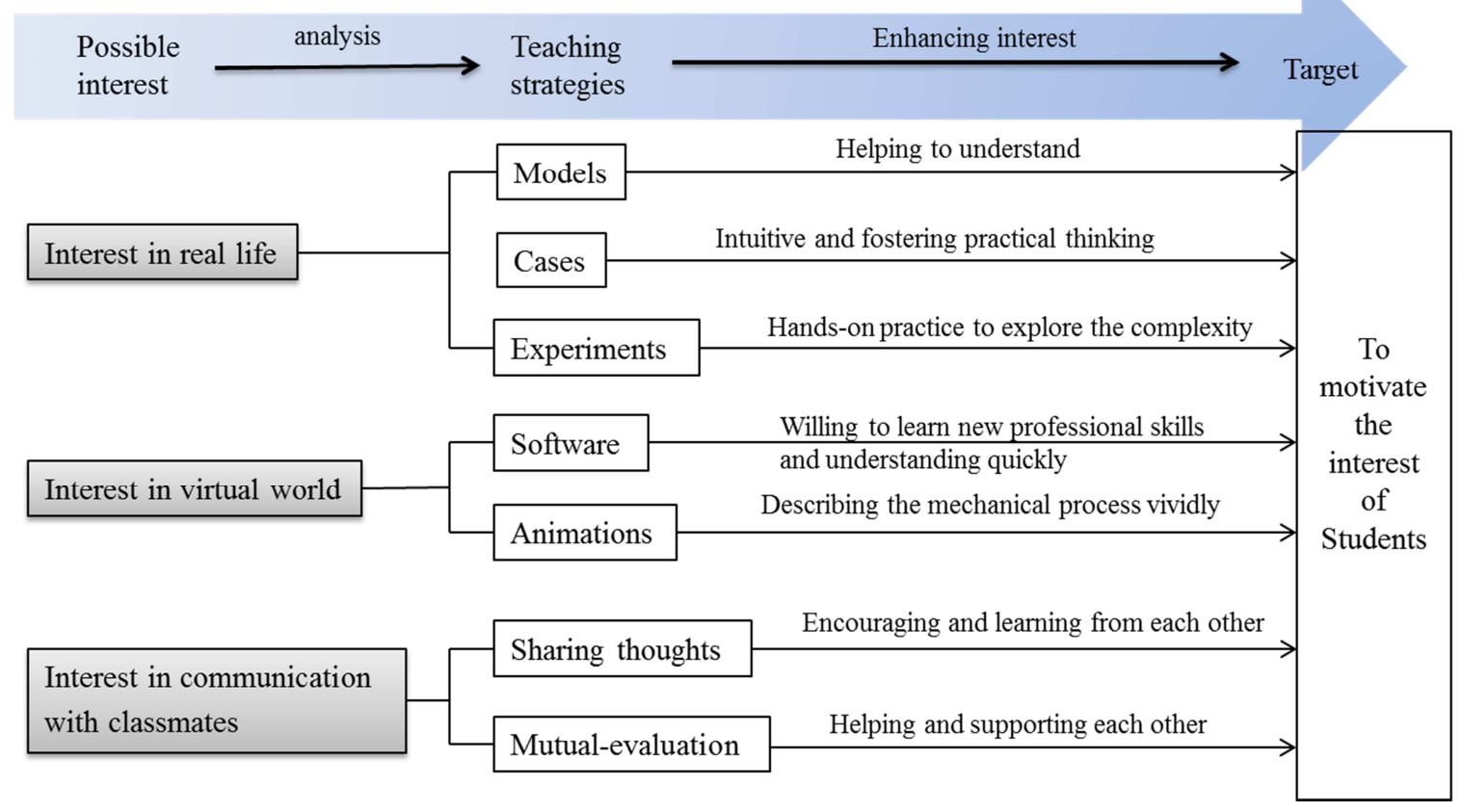

Figure 1. Interest of students and teaching strategies.

\subsection{Interest in Real Life}

Life is the best teacher. In classroom, it is easy to simplify the process of teaching by explaining abstract concepts with specific objects or things. At the same time, according to the characteristics of the contents of each chapter, different interest driven strategies can be adopted to make students interested in solving and exploring problems.

Specifically, from the traditional "verbal explanation" strategies to interest driven strategies, the material mechanics problems in real life, engineering practice and experiments are integrated into the teaching process. For example, when explaining the measures to improve the bending strength, the simple domestic automatic clothes hanger is used as a teaching tool to explain the design in the classroom. When explaining the principle of the buckling of struts, the cases of the collapse of the scaffolds are presented in the class, which attracts the interest of students and makes them understand the importance of the buckling of column under axial loading in the project. When explaining the deformation characteristics of bar under tension, the tensile experiments of metal materials are carried out in the lab, which deepens the impression and understanding of students of the tensile properties of metal materials. Besides, the backgrounds and many interesting stories about the classic problems in the history of material mechanics have been presented in the course, which enhances the interest of students in understanding these important classic problems. Also, it enriches the teaching content and inspires students' passion and sense of innovation in exploring new knowledge [5]. For example, a series of mechanics theorem, formula and mechanical constants like Saint Venant principle, Hooke's law, 
Euler formula, Young's modulus and Poisson's ratio that are named by famous scientists have been introduced through their lifetime stories and mechanical contributions, especially their research methods and character quality. Cantilever beam bending test carried out by Galileo, known as the father of scientific experiments, is well known in material mechanics. When Galileo is introduced, his contribution to the research method of natural science can be emphasized, that is, experimental observation, hypothesis, theoretical analysis and experimental verification. In addition, at the age of 74, Galileo completed his masterpiece work "Dialogues Concerning Two New Sciences" in prison [6]. Students can be inspired by the charm of his pursuit of truth.

\subsection{Interest in Virtual World}

Material mechanics study the law of internal force and deformation of rod under external force. It is very important for students to understand and master the distribution and change rules of these mechanical quantities to grasp the concept of mechanics. Although all these concepts have strict formulas, such calculations are often complicated, especially for students who just started learning mechanics of materials. The virtual simulation experiment is a very good solution. It can even solve the problems that are difficult to solve in the actual experiment, such as the stress measurement in any position. The virtual experiment can be carried out repeatedly without restriction [7]. To increase the interest in virtual world, virtual software platform was employed to demonstrate the behaviors of different components under different forces or loadings. The students can add the forces to the different components and the process of the deformation can be observed to help them to understand the stress and strain distribution and so on. A bolt under shear forces and a bending cantilever beam are carried out virtually in Figure 2. At the same time, series of animations are displayed to describe the mechanic process vividly and provided for student. Also, the symbols and the formulas are explained in the animations with explanations. It is very helpful and significant for students to understand the abstract concepts. In addition, the instructor can monitor the whole process of the students' experiment in real time in the background of system, correct the errors in the experiment in time, and evaluate the results of the experiment.

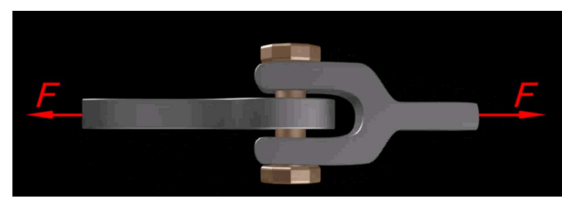

(a) A bolt under shear forces

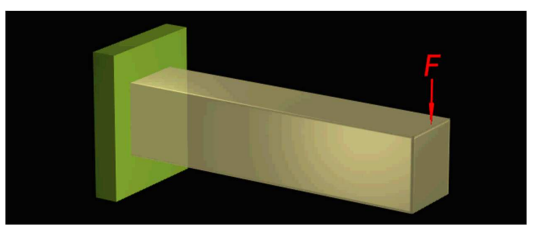

(b) A bending cantilever beam

Figure 2. Pictures in the virtual software platform.

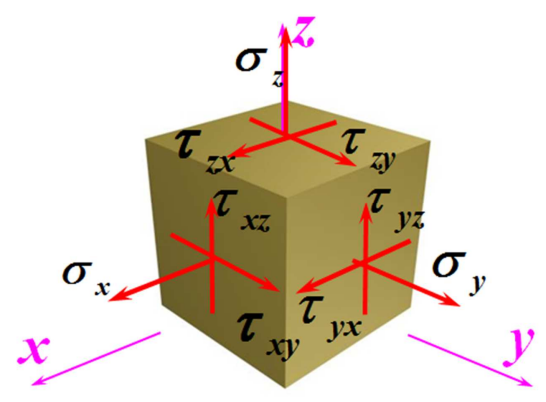

(a) Components of unit body

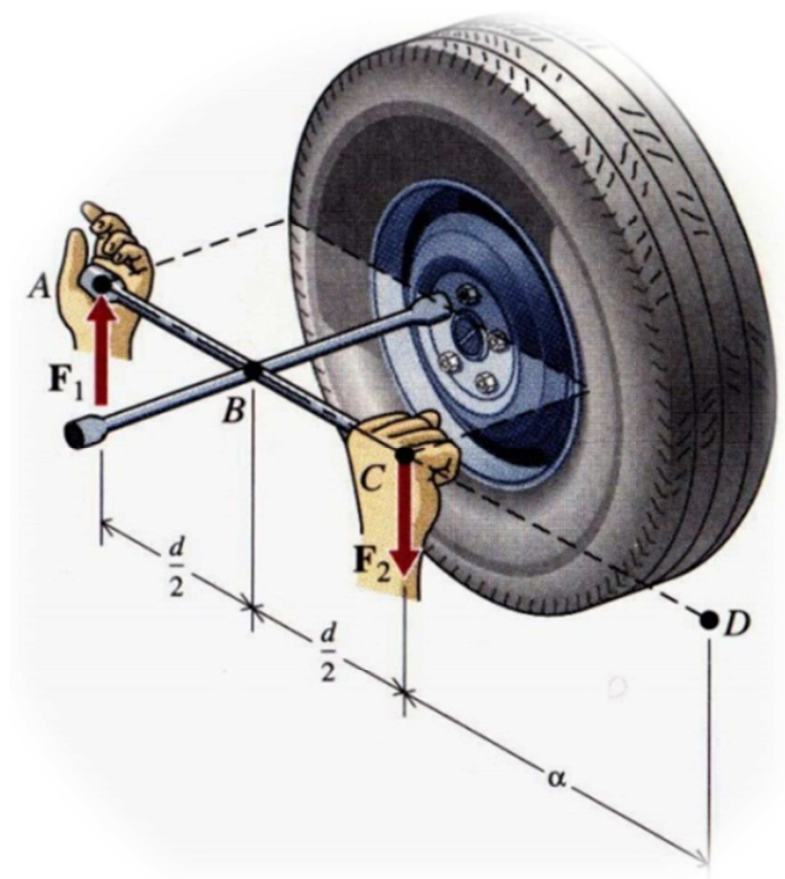

(b) Torsion and torque

Figure 3. Animations for describing the abstract concepts vividly.

\subsection{Interest in Communication of Classmates}

Good learning atmosphere is the good foundation of improving academic achievement and cultivating course interest. The interaction of students with other students not only increases motivation, but actually facilitates learning. This is the social perspective of student learning [8]. The course of material mechanics has many knowledge points and strong theoretical application. It is not easy for students to grasp the key and difficult points. According to the characteristics of the assignments, targeted strategies are implemented to stimulate the interest of students in learning. On the basis of the examples and exercises in the classroom, the homework and assignments after class, self-evaluation and peer-evaluation are the ways to speed up the understandings of students of the knowledge. These strategies let students have the opportunity to present the idea of their work, and also help the students to find out the deficiencies and disadvantages in their work [9]. Sometimes, the teacher can deliberately mistake the internal force drawing in explaining the examples. For instance, it is the basic work of the students to draw a 
bending internal force diagram in the mechanics of materials; however, they often make mistakes in drawing the bending diagram. In explaining the examples, we deliberately mistook a small amount of internal force diagram. Some students will raise objections. Then they are allowed to express their views or make modifications on the blackboard, at the same time, other students will think about this problem and discuss it enthusiastically at this time [10]. Moreover, they improve their presentation skills through sharing new ideas and new methods, asking questions and discussing freely. The interest of students is rising in the active atmosphere of the classroom.

\section{Conclusions}

For the students, attending a course without interest is a kind of torture. Therefore to raise the interest of learning for students is important. The interest driven teaching method is a concept, which can be implemented diversely from course to course and person to person. In this paper, the course of material mechanics was taken as an example. Material mechanics is an important and difficult course for students who major in engineering. In the classroom and teaching process, the close combination of theory and practice should be paid attention to. Practical cases and participatory practice can help students to make their learning goals clear. In a word, stimulate the interest of students every chance we get, then teachers and students will be happy in the teaching and learning process.

\section{References}

[1] Hong Lin, Lei Yang, Ruiyan Niu. Exploration and Practice on the Teaching of Material Mechanics Based on Case Driven [J]. Education Teaching Forum. No. 19, 2017, 5, pp167-168.
[2] Yuanyuan Li, Jianlin Zhang. On Application of Interest Driven Teaching Method in "Landscape Architecture Engineering Drawings" [J]. Journal of Southwest China Normal University, 2017.

[3] McDowell G R. A student-centred learning approach to teaching soil mechanics [J]. International Journal of Engineering Education, 2001, 17(3): 255-260.

[4] D. J. Nicol, Research on Learning and Higher Education Teaching. UCoSDA Briefing Paper Forty-five, April (1997).

[5] Shunying Ji, Jinying Wu, Hongyan Ma. The Integration and Practice of Knowledge of Mechanics History in Teaching Mechanics of Materials [J]. Higher Education of Sciences. No. 4, 2012, pp137-164.

[6] Galilei G. Dialogues concerning two new sciences [M]. Dover, 1914.

[7] Xia Li. Research and development of virtual experiment system of material mechanics [J]. Experimental Technology and Management. Vol. 33, No. 12, 2016. Pp125-127..

[8] Nataša Junež. The Use of Information and Communication Technology to Promote the Interest of Learning Chemistry [J]. Science Journal of Education. Vol. 5, No. 5, 2017, pp. 220-224. doi: $10.11648 /$ j.sjedu.20170505.17

[9] Holland C, Muilenburg L. Supporting student collaboration: Edmodo in the classroom $[\mathrm{C}] / /$ Society for Information Technology \& Teacher Education International Conference. Association for the Advancement of Computing in Education (AACE), 2011: 3232-3236.

[10] Chao Huang, Dehua Liu, Jianhua Wu, Qian Yu. Experience of improving teaching quality of mechanics of materials course $[\mathrm{J}]$. Journal of Architectural Education in Institutions of Higher Learning. Vol. 20, No. 5, 2011. pp88-91. 